\title{
Metoidioplasty using labial advancement flaps for urethroplasty
}

\author{
Toby R. Meltzer, Nick O. Esmonde \\ The Meltzer Clinic, Scottsdale, AZ 85253, USA. \\ Correspondence to: Dr. Toby R. Meltzer, The Meltzer Clinic, 7025 N Scottsdale Rd. Ste 302, Scottsdale, AZ 85253, USA. \\ E-mail:tmeltzer@tmeltzer.com
}

\begin{abstract}
How to cite this article: Meltzer TR, Esmonde NO. Metoidioplasty using labial advancement flaps for urethroplasty. Plast Aesthet Res 2020;7:61. http://dx.doi.org/10.20517/2347-9264.2020.122
\end{abstract}

Received: 22 May 2020 First Decision: 12 Aug 2020 Revised: 2 Sep 2020 Accepted: 10 Oct 2020 Published: 6 Nov 2020

Academic Editor: Marlon E. Buncamper Copy Editor: Cai-Hong Wang Production Editor: Jing Yu

\begin{abstract}
Aim: A variation of the ring metoidioplasty has been performed for masculinizing transgender surgery by the senior surgeon since 2010. It does not require buccal grafts or vaginal wall flaps. An excisional vaginectomy was completed in all patients. We sought to evaluate the urologic outcomes and complications for this technique. Further, we provide a detailed technical description of the technique, including ancillary masculinizing procedures.
\end{abstract}

Methods: This is a retrospective, single surgeon chart review of all patients undergoing metoidioplasty from 2010 to 2020. Demographics, outcomes, and complications are reported. A self-reported patient questionnaire provided data on patient-perceived urologic outcomes.

Results: Ninety-one patients were included in the study, with 80 (87.9\%) patients reporting ability to stand and void with a strong stream. We observed five strictures (5.5\%) and one fistula (1\%). Scrotoplasty with tissue expanders and testicular implants were performed in 75 (82.4\%) patients, while monsplasty was performed in 54 (59\%) patients.

Conclusion: Our technique has a low complication rate and patients report a strong urinary stream and the ability to stand in the large majority of cases. Ancillary masculinizing procedures are common. The limitations of metoidioplasty, in general, still persist, which are the small phallus size and variable ability to clear the zipper without lowering the pants to void.

Keywords: Metoidioplasty, urethroplasty, transgender surgery, transmasculine surgery

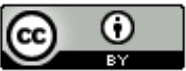

(c) The Author(s) 2020. Open Access This article is licensed under a Creative Commons Attribution 4.0 International License (https://creativecommons.org/licenses/by/4.0/), which permits unrestricted use, sharing, adaptation, distribution and reproduction in any medium or format, for any purpose, even commercially, as long as you give appropriate credit to the original author(s) and the source, provide a link to the Creative Commons license, and indicate if changes were made.

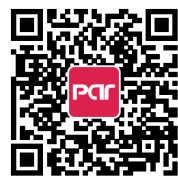




\section{INTRODUCTION}

The surgical treatment of gender dysphoria related to genital anatomy for transmasculine patients is largely achieved via phalloplasty or metoidioplasty. Both techniques offer masculine anatomy and the potential to urinate while standing. However, there are some inarguable downsides to phalloplasty, namely a large scar burden, more potential immediate and long-term urologic and flap complications, greater number of procedures, less predictable sensory and sexual function outcomes, and relatively few surgeons and centers providing the procedure, that motivate some patients to pursue less extensive genital reconstruction. Thus, metoidioplasty is an appealing alternative for some patients.

Metoidioplasty aims at masculinizing the genitalia by making the hypertrophied clitoris appear as a penis and may also include urethral lengthening and scrotoplasty.

While there are now several variations, most published reports of this technique describe the release of the urethral plate and dorsal suspensory ligaments of the clitoris to facilitate lengthening ${ }^{[1-4]}$. The defect created by dividing the urethral plate is typically grafted with either vaginal or buccal mucosa, and possibly buttressed with local flaps. Further, anterior vaginal wall flaps harvested during vaginectomy may be utilized for construction of the proximal portion of the pars fixa ${ }^{[5]}$.

A novel variation of the metoidioplasty technique was presented by Takamatsu et al. ${ }^{[6]}$, who described raising a large mucosal flap and tubularizing it in continuity with the anterior vaginal wall flap to create the pars fixa, dubbed the "labial ring flap" (also referred to here as "ring metoidioplasty"). The flap is anteriorly based and includes the urethral plate and entire mucosa of the inner labia including the tissue adjacent and posterior to the vagina and urethral meatus. Their flap design excluded the vaginal and urethral tissues and thus creates a "ring" of absent tissue within the flap that is subsequently closed. This flap allows for the entirety of the neourethra to be comprised of vascularized tissue and spares the need for additional grafts. In their series, most patients did not have a vaginectomy prior to metoidioplasty, which may have increased their occurrence of urethral complications ( 3 strictures and 12 fistulas in 43 patients). Here, the senior author has further modified the Takamatsu technique to eliminate the need for the vaginal flap and reconfigured the labial flap to be two large V-Y adipo-mucosal advancement flaps which form the entirety of the lengthened urethra. This paper reviews the senior author's experience with the technique, including a technical description, perioperative care, patient demographics, surgical outcomes, and secondary procedures.

\section{METHODS}

The study is a retrospective chart review of a single surgeon's experience performing metoidioplasty using V-Y labial flaps between 2010 and 2020. All patients gave informed consent. Inclusion criteria were age greater than 18, diagnosis of gender dysphoria, and compliance with World Professional Association for Transgender Health guidelines for genital surgery. Most patients self-referred for a metoidioplasty. Their rationale for choosing metoidioplasty over phalloplasty was not recorded. There was no strict body mass index (BMI) "cut off" to qualify for metoidioplasty; however, if the patient was an active tobacco user that was an absolute contraindication. It is the senior author's practice that all patients undergo vaginectomy and colpoclesis immediately prior to the metoidioplasty. Additionally, the senior author preferred all patients were established on exogenous testosterone therapy prior to surgery to realize the most benefit from clitoral hypertrophy. Patient demographics and surgical data, ancillary procedures, urologic outcomes, and complications were collected. Follow up data included self-reported urologic outcomes, using an ad hoc questionnaire that was administered in person or via phone. Patients were first asked whether they were able to stand and urinate ("yes/no"), and then whether their urinary stream was "strong" or "weak". These questions were asked at all visits, but we chose the patient response from their most recent or final 
postoperative visit. For the analysis, we generated descriptive statistics using the mean and standard deviation for continuous variables, and the frequency and percentage for binary variables using Excel (Microsoft Corp. Richmond, WA).

\section{Perioperative care and operative technique}

The metoidioplasty begins after an excisional vaginectomy is completed with the patient in low lithotomy. If not previously done, a laparoscopic assisted hysterectomy and oophorectomy are completed before the vaginectomy. An episiotomy facilitates the vaginectomy so the posterior fourchette is already divided at this point. The vaginal lining has been removed and closed down with sutures leaving a 2 -cm cuff of mucosa on the ventral urethra.

A suture is placed through the glans clitoris to maintain tension. Tacking sutures are placed on the edge of the labia minora to spread out the inner surface of the labia minora and widely expose the urethral plate. Below the level of the urethra, the flaps are each designed to be a minimum of $12 \mathrm{~mm}$ in width. This is measured from the innermost edge at the vaginectomy site and extends as far laterally as necessary. The medial border of the flap will extend just lateral to the urethra, making sure to preserve the location of ducts of Skenes glands (lesser vestibular glands) [Figure 1A]. The flaps will join at the midline immediately above the urethral meatus. The midline is marked from this point up to the glans clitoris, and the flap is marked on either side with a width of $12 \mathrm{~mm}$ ( $24 \mathrm{~mm}$ total width). If the labia minora are very small or attenuated distally, the flap can be designed to cross the labial edge over to the preputial skin. The labial edge can be unfolded later when elevating the flap and the preputial skin will be the lateral edge of the urethral flap. The lateral border of the flaps should gently curve outward above and below where the labial flaps unite in the midline. This helps to prevent an area of narrowing and reduces tension where the paired flaps are sewn together. This modification was made after early experience of this area being a repeat locus for stricture. Subsequently, stricture frequency decreased. Local anesthesia (1\% lidocaine with 1:100,000 epinephrine) is infiltrated throughout the planned flaps. A cystoscope is used to confirm that there is no bladder injury from the vaginectomy and allows a percutaneous suprapubic tube to be placed under direct visualization.

Beginning posteriorly, the flaps are incised and elevated deeply (including fat) with scissors. When the flaps are elevated just superior to the urethra, the dissection then extends deeply to the corporal bodies and extends superiorly along the corporal bodies. The urethral plate is undermined releasing the ventral chordee until no restriction to straightening is felt [Figure 1B]. While upward traction is held on the clitoris, applying digital pressure to ventral clitoris one can appreciate the loss of bowstringing of the urethral plate and it should feel flat against the straightened corporal bodies. Usually, the urethral plate will be released between 3 and $5 \mathrm{~cm}$ in length (measured anterior to posterior). The labial flaps are incised distally beyond this, but not undermined to maintain the blood supply through the urethral plate via anterior branches of the external pudendal artery. The clitoral skin lateral to the mucosa is elevated as needed to reduce the redundancy and allow tension free wrapping of the skin over the urethra in the mobile (pendulous) portion of the clitoris. There is usually an excess of skin and this can be de-epithelialized later to help cover the neourethra. The skin around the corona of the glans is not incised, giving the penis an uncircumcised appearance. A running, locking 4-0 Monocryl (Ethicon Inc., Sommerville, NJ) suture is used to over sew the raw surface area where the urethral plate was released on the ventral corporal bodies. There are frequently several larger venous plexuses below where the flaps have been elevated proximally, which are also over sewn with 4-0 Monocryl.

With mild tension on the glans, the labial flaps should easily reach below the urethral meatus. Most often, the mucosa is then removed from the ventral portion of the urethra leaving 1-cm cuff to sew. If it appears the flaps will not reach, then a posterior flap can be elevated instead - but this has not been necessary. The 

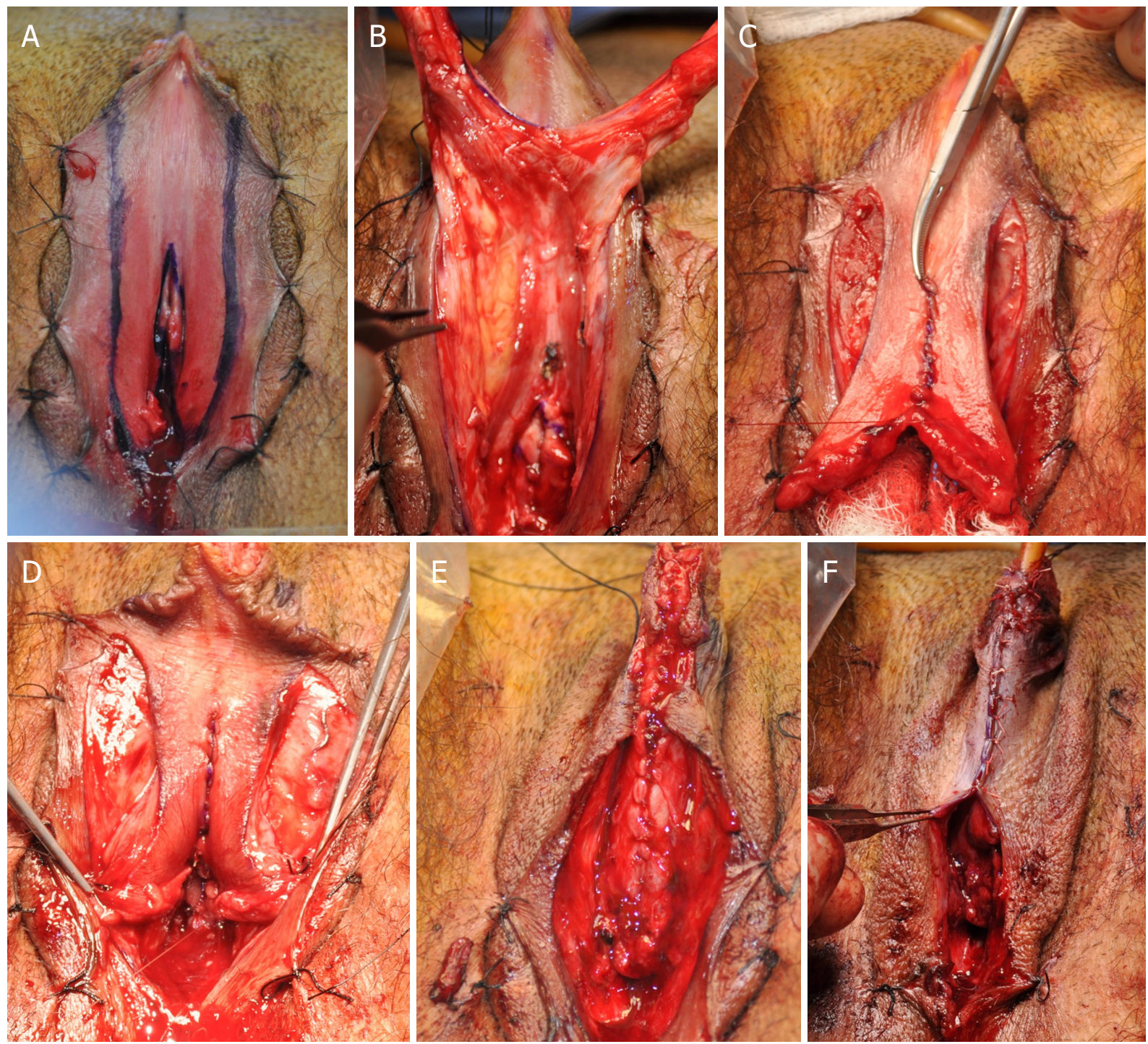

Figure 1. A: Standard markings for metoidioplasty technique; B: ventral chordee released and flaps elevated. Bulbospongiosus muscles and corporal body visible on deep side; C: ventral urethral repair ( $\mathrm{V}-\mathrm{Y}$ configuration); D: native urethra to neourethra repair; E: completed urethral repair over $14 \mathrm{~F}$ catheter; F: paramedian skin closure

epithelium of the flaps is imbricated in all suturing of the neourethra. The medial edges of the flaps are sewn together with running 4-0 Monocryl stopping when it reaches the dorsal urethra without tension [Figure $1 \mathrm{C}$ ]. The flaps are now sewn around the native urethra, with 3-0 interrupted Monocryl [Figure 1D]. Once completed, a $14 \mathrm{~F}$ catheter is placed and the lateral border of the flaps are rolled over the catheter and approximated with interrupted 3-0 Monocryl (with the knots facing away from the urethral lumen), creating the ventral wall of the neourethra. As the suturing proceeds distal to the pars fixa, a 4-0 Monocryl suture is used. The urethra is repaired as far distal as possible provided there is no tension on the repair over the catheter. Depending on the size of the glans clitoris, the urethroplasty will usually terminate at or just distal to the base of the glans.

The levator ani muscles in the vaginectomy site are now approximated in the midline snuggly with 2-0 Monocryl. Approximating the muscles provides hemostasis at the vaginectomy site and buttresses the ventral and proximal urethra to help prevent diverticulum and fistulas. A single TLS drain (Stryker Corp., Kalamazoo, MI) is placed along the urethra and brought out superiorly. The remainder of the vaginectomy 


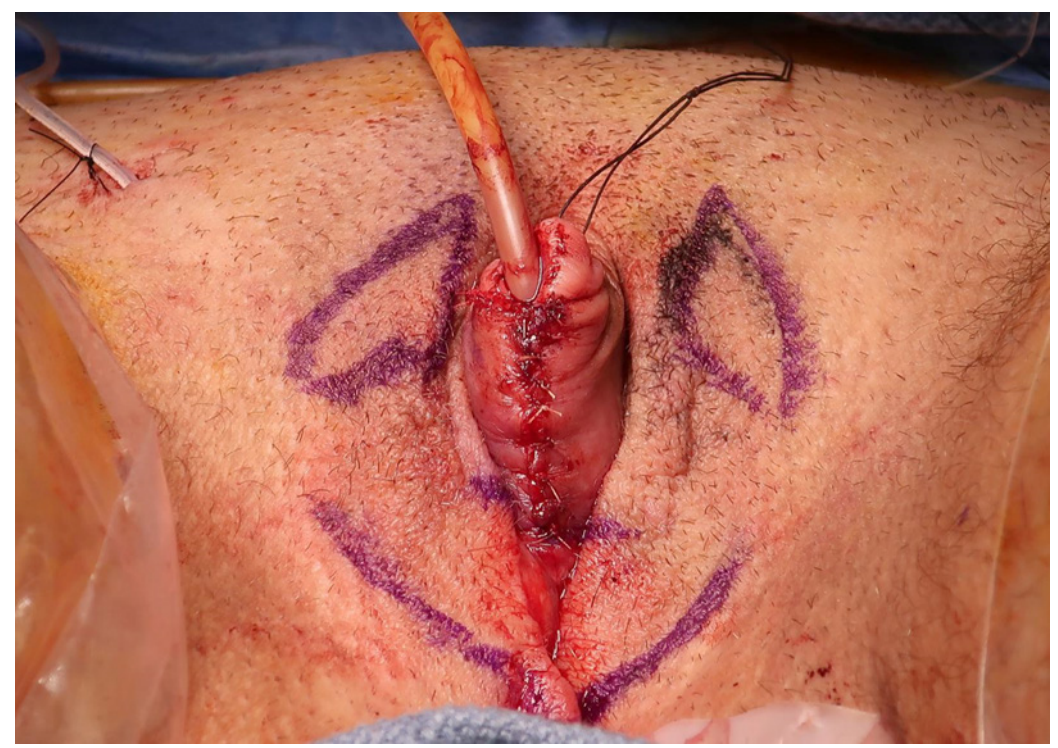

Figure 2. Scrotoplasty markings

site is closed in layers over the pars fixa. The subcutaneous loose areolar tissue can be approximated at the base of the mobile portion of the urethra. The lateral skin of the clitoris from one side is brought across the midline creating a paramedial skin closure so that it does not lay directly over the urethral repair [Figure $1 \mathrm{E}$ and $\mathrm{F}$ ]. There is usually an excess of skin on either side which can be de-epithelialized before the closure and folded over the urethra for more coverage. The final skin repair is competed with interrupted 4-0 Vicryl (Ethicon Inc., Sommerville, NJ) along the edges of the clitoral skin, to wrap the neo-phallus.

If a scrotoplasty is going to be performed at the same time, a variation of the scrotoplasty described by Selvaggi et al. ${ }^{[7]}$ is used [Figure 2]. The labia majora flaps are designed similarly, but not advanced as far anteriorly as with a phalloplasty to prevent the scrotum from engulfing and obscuring the metoidioplasty. A transverse incision around $30 \mathrm{~mm}$ in length is made at the base of the penis below the midline suture line to inset the tip of the labial flaps. The lateral incision stops at about the level of the base of the penis or lower if there is excessive tension for a midline repair. The upper portions of the anterior labia are reduced separately with either an inverted $\mathrm{V}$ to $\mathrm{Y}$ excision or an asymmetric triangle excision to flatten the penopubic junction and make the penis more visible and accessible.

At the completion of the procedure, the catheter in the penis is plugged and taped against the abdomen to reduce pressure on the urethral suture line. The suprapubic tube is maintained to gravity drainage. The patient is maintained on bedrest until Postoperative Day (POD) 2 to decrease the risk of bleeding. On POD 12, the Foley catheter is removed, and the patient is allowed to void through the neourethra. Total output, void times, and post-void residuals are recorded. When the post-void residuals are consistently low $(<30 \mathrm{~mL})$, the suprapubic tube is removed. Occasionally, higher post-void residuals are seen and are more common after the first void in the morning. If the patients have persistently higher post-void residuals and/or slower voiding times, then tamsulosin (Sanofi-Aventis SA, Cambridge, MA) is given. It has been the senior author's experience that, for the majority of patients, tamsulosin will increase their flow rate and reduce their post-void residuals, although this is an off-label use. If effective, a two-week course of tamsulosin is prescribed and the suprapubic tube is removed. There are occasional patients who have persistently higher post-void residuals regardless with a stable trend. As a trial, the suprapubic tube is plugged for $24 \mathrm{~h}$ and then the post-void residual is checked prior to removal. Early strictures have not occurred; however, if there is any concern, it is prudent to leave the suprapubic catheter in place longer. The patient will continue to void through the neourethra, and the suprapubic tube is kept plugged. 


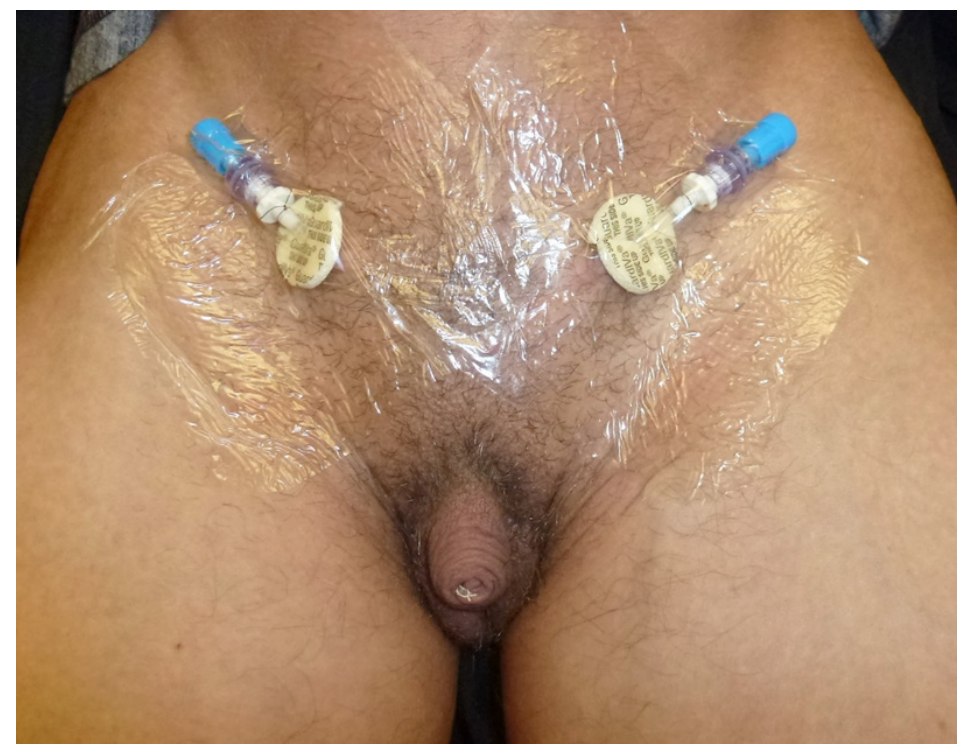

Figure 3. Postoperative photo showing externalized testicular tissue expander ports

Tissue expanders have been used to enlarge the scrotum prior to implantation of testicular prostheses (Implantech, Sydney, Australia). Regardless of the timing of scrotal construction, placement of implants or tissue expanders is delayed for three months after the metoidioplasty to allow the neourethra to heal well without external pressure. If the scrotoplasty is performed as a secondary procedure, then the testicular implants or scrotal expanders can be placed at this time. Two weeks after implantation, the patient starts inflating them at home using 1-2 $\mathrm{mL}$ every other day. Expansion is stopped at $50 \mathrm{~mL}$ total in most cases. At least one month after completion of expansion, the permanent testicular implants are placed. The tubing from the expanders has been exteriorized on the mons with a two-way valve in response to some issues with compliance and irritation [Figure 3].

The reduction of the mons is another important adjunct. It masculinizes the mons by making it flatter, gives more definition to the penopubic junction, and positions the penis further forward. The mons resection is not done at the index metoidioplasty because of the anterior positioning of the mons skin and advancing the penis forward would increase the tension on the neourethra at the junction of the native urethra. Instead, it is done as an isolated procedure at least six weeks prior to metoidioplasty or at their final stage, during permanent testicular implant placement. We offer a monsplasty prior to metoidioplasty (at least six weeks) for patients with higher BMI or patients who have had significant weight loss with subsequent mons ptosis. The mons resection in this group will need to be a more extended excision. By performing this procedure, we try to avoid some of the issues that arise after monsplasty where patients are dissatisfied with appearance and/or urinary function. An earlier monsplasty thus facilitates better exposure of the phallus and improves the ability to stand and urinate after subsequent metoidioplasty. An elliptical excision of skin is designed $7 \mathrm{~cm}$ above the top of the penopubic junction. The limited amount of skin to be removed is estimated by grasping upwards from the lower marking [Figure 4]. The preference is to keep the final scar within the pubic hair pattern, if possible. After excising the skin, the sub-Scarpa's fat is directly excised inferior to the incision and down to the pubic symphysis using cautery. Liposuction with aggressive cannulas has also been used to reduce the fat. The dorsal suspensory ligament is released at this time. For the patients with a greater BMI, they benefit from tacking sutures with o Prolene (Ethicon Inc., Sommerville, NJ) around the penopubic junction, similar to procedures performed for a buried penis indication. These sutures are placed through Scarpa's fascia, close to the dermis and anchored to the pubis and anterior rectus sheath following the fat removal. This will cause visible puckering at each suture site 


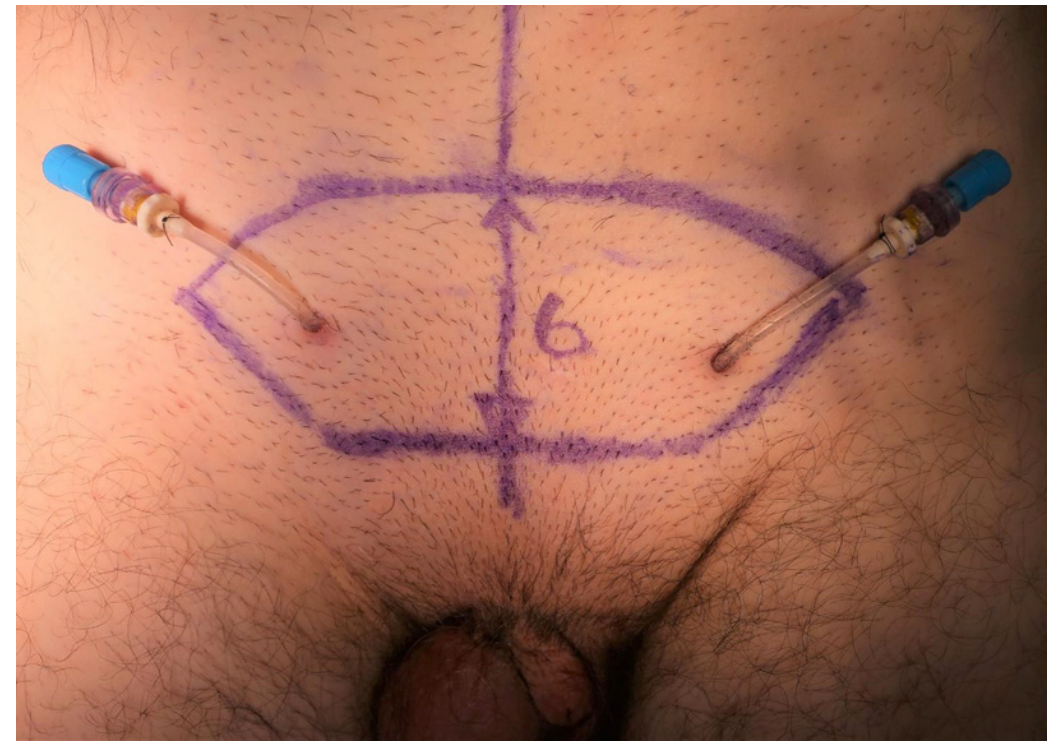

Figure 4. Monsplasty markings
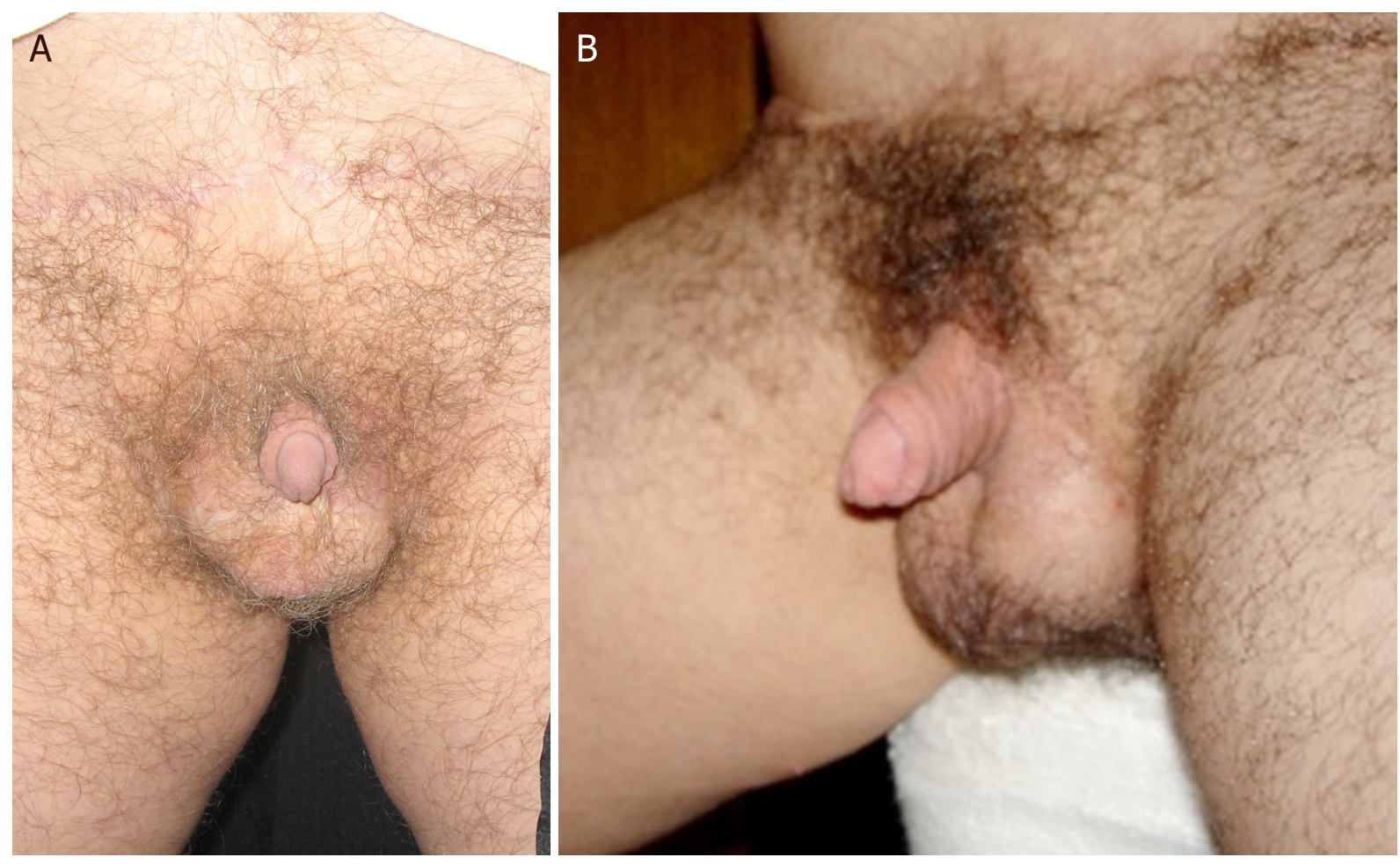

Figure 5. A: Completed metoidioplasty, including scrotoplasty, testicular implants, and monsplasty (frontal view); B: completed metoidioplasty, including scrotoplasty, testicular implants, and monsplasty (oblique view). Patient in Figure 5B is not same patient as Figure 5A

which will resolve. These secondary procedures work to accentuate the aesthetics and function of the final metoidioplasty reconstruction [Figure $5 \mathrm{~A}$ and $\mathrm{B}$ ].

\section{RESULTS}

In total, 91 patients met inclusion criteria for the study between 2010 and 2020. The mean age was 39.8 years $(\mathrm{SD}=12.6)$, with all patients well established on testosterone prior to surgery [Table 1]. Of those 91 
Table 1. Demographic data $(n=91)$

\begin{tabular}{lc}
\hline Characteristic & Mean (SD) or No (\%) \\
\hline Age & $39.8(12.6)$ \\
BMI & $25.9(4.3)$ \\
Duration testosterone (months) & $87.8(79.8)$ \\
Previous hysterectomy and oopherectomy & $46(50.5)$ \\
Hysterectomy/oopherectomy at time of metoidioplasty & $45(49.5)$ \\
\hline
\end{tabular}

Table 2. Secondary procedures following metoidioplasty $(n=91)$

\begin{tabular}{lcc}
\hline Procedure & Mean (SD) or No (\%) \\
\hline Scrotoplasty* & $75(82.4)$ \\
TE + TI & & $75(82.4)$ \\
TI & & $68(74.7)$ \\
Monsplasty & $54(59.3)$ \\
& & 24 \\
& BMI 18-25 & 19 \\
& BMI 25-30 & 9 \\
& BMI 30-35 & 2 \\
\hline
\end{tabular}

*Have had or are scheduled to have scrotoplasty. TE: tissue expanders; TI: testicular implants

Table 3. Urologic complications $(n=91)$

\begin{tabular}{lll}
\hline Description & No (\%) \\
\hline Fistula & Surgical revision & $1(1)$ \\
& Spontaneously closed & 0 \\
Stricture & & $1(1)$ \\
& Stricture repair & $5(5.5)$ \\
& Dilation and urethrotomy & $2(2.2)$ \\
& & $3(3.3)$ \\
\hline
\end{tabular}

patients, $75(82.4 \%)$ patients underwent at least one secondary procedure [Table 2]. The most common secondary procedure was placement of scrotal tissue expanders followed by scrotal implants $(82.4 \%)$. A monsplasty was performed in $54(59.3 \%)$ patients and was indicated in a wide range of BMIs. Mean followup for all patients was 15.4 months.

The urologic complications are listed in Table 3. The most common complication was a stricture in five patients (5.5\%). Two of these strictures were treated with buccal mucosa graft at the stricture site after one internal urethrotomy and dilation failed. One of those patients had a stricture recurrence, and ultimately underwent a perineal urethrostomy and secondary closure without buccal mucosa. The three other patients were treated with intermittent self-dilation following a single urethrotomy.

There were $80(87.9 \%)$ patients who reported being able stand and urinate with a strong stream [Table 4 ]. Two patients reported a strong stream, even if they were unable to urinate while standing.

While sexual function outcomes were not studied in depth, no patients reported a change in ability to orgasm by clitoral stimulation following the procedure.

\section{DISCUSSION}

Metoidioplasty is a reliable procedure for creating a small phallus that allows patients to stand and urinate $^{[s]}$. There exist several variations of this procedure around the world and relatively few practitioners. Our approach is a novel modification of the Takamatsu technique ${ }^{[6]}$. We propose that the primary 
Table 4. Self-reported urologic outcomes $(n=91)$

\begin{tabular}{llc}
\hline Description & Mean (SD) or No (\%) \\
\hline $\begin{array}{l}\text { Able to stand and void } \\
\text { Quality urinary stream }\end{array}$ & $80(87.9)$ \\
& & \\
& Strong & $82(90.1)$ \\
& Okay & $3(3.3)$ \\
& Weak/erratic & $3(3.3)$ \\
& Unknown & $3(3.3)$ \\
\hline
\end{tabular}

advantages of this technique are that it achieves urethral lengthening without additional grafts or the anterior vaginal wall flap, which is prone to diverticulum and distension. Furthermore, we found that the use of tubularized vascularized flaps is less prone to stricture and fistulae, likely owing to their robust blood supply and the geometry of the suture line. Variations of the ring technique have been utilized by other centers ${ }^{[9,10]}$, but to our knowledge this is the first report to describe the technique and report on the outcomes. Indeed, we found that a large majority (87.9\%) of patients were able to stand and urinate (primary outcome). Thankfully, complications were relatively rare. We found that five patients experienced either a fistula $(1 \%)$ or stricture $(5.5 \%)$. Two of the strictures required urethral reconstruction and three were treated with a single internal urethrotomy and intermittent self-dilation, based upon patient preference. To our knowledge, they have not had any stricture recurrence. After two early strictures in this series, the senior author modified the lateral border of the labial flaps to gently curve outward just above and below the urethra. This prevents tightness and subsequent stricture formation at this location, which is distal to the junction of native and neourethra. Secondary procedures are common with metoidioplasty, with scrotoplasty, followed by testicular tissue expanders and testicular implants being most frequently performed (82.4\%). While the available data made it impossible to comment on whether patients went on to subsequent phalloplasty after metoidioplasty, the follow up we do have showed this was a very uncommon event. For the patients who did have a phalloplasty at our centers, our metoidioplasty technique is easily coapted to the neourethra of the phalloplasty.

The published outcomes for urologic complications following metoidioplasty indicate stricture rates up to $50 \%$ and fistula rates up to $75 \%^{[10-12]}$. This is substantially higher than what we found in our series, where strictures occurred in $5.5 \%$ of patients, and fistulas in $1 \%$. Admittedly, there is considerable heterogeneity in the surgical techniques used and how to classify complications. This makes it hard to compare techniques and even make comparisons with phalloplasty outcomes, for those patients who are weighing the risks of each procedure ${ }^{[13,14]}$. When patients request a metoidioplasty, we believe that they are seeking the most reliable technique for standing to void, with the least recovery and scar burden. In the systematic review by Frey et al. ${ }^{[15]}, 89 \%$ of patients reported the ability to stand and urinate following metoidioplasty, which is similar to our findings. We found $87.9 \%$ of patients were able to stand and urinate, and $90 \%$ of patients overall reported a strong stream. The urologic history that is completed in advance of the procedure helps identify patients who may have more trouble with urethral lengthening. Further urologic work up and urodynamic studies are indicated in patients who have frequent urinary tract infections, low flow rates, atypical voiding patterns (stopping/starting or incomplete emptying), or stress/urgency incontinence. This is helpful in identifying patients who may have problems exacerbated by the urethral lengthening and appropriately counselling them. It may also help explain an unusual voiding pattern following the procedure.

We believe there are several features of our technique which may explain the relatively low rate of urologic complications. The urethral lengthening is constructed entirely of vascularized tissue with a robust, retrograde blood supply ${ }^{[6,16]}$. The flaps are thick, with some underlying subcutaneous tissue, and are easily mobilized to create a tension free urinary conduit. Posteriorly (at the anastomosis with the native urethra), the flaps are brought together in a V to Y configuration, which adds some length to the construct. 
This avoids a narrow circumferential suture line at the junction of the native and neourethra. The senior author has found this junction to be a common site for stricture, in revision surgery for patients who underwent metoidioplasty elsewhere. In our technique, we avoid different types of tissue grafts/flaps, and orient the suture line in an anterior-posterior direction, which we believe contributes to our relatively low rate of urethral complications. While the track record for buccal grafts in urethral reconstruction is well established ${ }^{[17]}$, it is, nevertheless, a graft, which takes longer to heal and is more prone to contracture and possible graft loss. Moreover, the use of buccal graft can make it difficult to get a watertight closure along the urethral lengthening. We have seen even small areas of poor graft take or healing to contribute to fistulas in this area. The donor site for buccal grafts is painful initially and carries some morbidity long term ${ }^{[18]}$. Multiple authors describe the use of the anterior vaginal wall flap ${ }^{[2-4,19,20]}$, including the original Takamatsu paper ${ }^{[6]}$. In theory, it is appealing to utilize this vascularized, local tissue. However, we have found that these flaps may be problematic. The flap - with its redundant folds and broad-based geometry ${ }^{[5,19]}$ - can create a large diverticulum proximal to the urethra and cause issues with siphoning of urine and incomplete emptying ${ }^{[21]}$. This results in more post-void dribbling, increased risk for urinary tract infections, and weakened urinary stream. For patients who had the vaginal wall flaps and subsequently underwent a phalloplasty, these thin walled and distensible flaps increased the pressure needed to achieve a normal urinary stream. Due to the myriad issues, the vaginal wall flaps were abandoned in 2010 by our center.

At least one secondary procedure was performed in $82.4 \%$ of our patients, with tissue expanders followed by testicular implants being the most common [Table 2]. Tissue expansion for masculinizing surgery has been described for some time ${ }^{[22]}$, but it does not appear to be in widespread use and is even argued against by some groups ${ }^{[5,7]}$. Further, reports on the use of testicular implants in transgender men is rare. Hage et al. ${ }^{[4]}$ reported using testicular implants alone in their series of 70 metoidioplasties. Their most common issues were malposition (50\%) and implant loss (30\%-35\%, depending on whether the scrotoplasty was performed primarily or secondarily). While we did not record testicular complications in this study, we have found that expanding the scrotal flaps decreased our need for malposition revision. Tissue expansion improves blood supply to skin flaps, so we suspect this may also improve implant loss rates through better healing and tissue durability. At our center, we began to perform scrotoplasty at the same stage as the metoidioplasty beginning in 2017. While some worry about compromised blood supply of concurrent labial flabs for both the metoidioplasty and scrotoplasty, we did not see any evidence of this. In fact, with an anteriorly based scrotoplasty, there is a robust blood supply that can support these flaps during the first operation. In response to some injection site infections and patient compliance issues, when tissue expanders were indicated, we began externalizing the ports to allow greater ease of fill. Prior to converting to a variation of the Selvaggi technique ${ }^{[7]}$, the scrotoplasty was performed as a separate procedure a minimum of three months following the metoidioplasty. This was a posteriorly-based design and gives excellent definition to the penoscrotal junction. However, there is a tendency to make the scrotum too posterior. The Selvaggi technique has the advantage of lengthening the perineal body and advancing the scrotum forward. It is important not to advance the flaps too far forward with the perineal closure because it will engulf the penis. The fullness of the labia majora anteriorly will need to be separately reduced to flatten the penopubic junction. Reduction of the anterior labia majora is performed at the same time as the metoidioplasty and may be reduced further when the testicular implants are placed. Aggressive fat excision around the final closure is also done at this time.

Patients with higher BMIs with thicker mons or those who have had a significant weight loss can benefit from a mons resection at least six weeks prior to metoidioplasty instead of during their final stage (which is typically scrotal implant placement). This makes the phallus more accessible and can facilitate standing to void for patients who would otherwise be dissatisfied with their immediate postoperative results. Fiftyfour of our patients (59\%) underwent monsplasty, the majority $(79.6 \%)$ of whom had a BMI less than 30. 
This underscores our observation that BMI alone is not a useful indicator for who would benefit from a monsplasty postoperatively. Rather, the clinical exam and goals of the patient should guide this choice.

As phalloplasty has gained increasing attention in the gender surgery literature, metoidioplasty has not enjoyed the same ascendant profile. Achieving reliable urologic and sensory outcomes without the morbidity and time commitments of a phalloplasty is a clear benefit of metoidioplasty. Moreover, minimizing scar burden, recovery time, and distant donor sites also favor metoidioplasty. While our patient population present to consultation with a uniquely thorough level of understanding of the procedures available, this difference between phalloplasty and metoidioplasty is an essential part of the consultation. We describe a novel variation of the ring flap metoidioplasty and found that we could achieve low rates of complications while observing high rates of ability to stand and urinate with a strong stream. Concurrent scrotoplasty can be safely performed and secondary procedures are common for patients desiring complete genital masculinization. The high rate of secondary procedures also allowed us to objectively evaluate the status of the urethra at that time, if there were any voiding issues reported. There are, however, several limitations to this study. Many patients travel for these procedures, so it is possible that complications or other secondary procedures were managed elsewhere. Our patient questionnaire was not performed at a standardized time interval, so it is possible we captured these data before they developed any urologic issues. Finally, there were some modifications to the technique made over the study period, including the widening of the labial flaps, the use of external tissue expander ports, and the conversion to an anterior based scrotoplasty. This heterogeneity may make strict comparisons between techniques more difficult.

\section{DECLARATIONS}

\section{Acknowledgments}

The authors would like to thank Jeremey Ballard for his assistance in data acquisition.

\section{Authors' contributions}

Development of surgical technique, data acquisition, study design: Meltzer TR

Data analysis and interpretation, manuscript preparation: Meltzer TR, Esmonde NO

\section{Availability of data and materials}

The data used for the study will not be made publicly available. The database contains proprietary information, including intellectual property, that the authors do not wish to share.

Financial support and sponsorship

None.

\section{Conflicts of interest}

Both authors declared that there are no conflicts of interest.

\section{Ethical approval and consent to participate}

This was an anonymous, retrospective study of a deidentified dataset. Patients provided informed consent for inclusion in research at the time of establishing care.

\section{Consent for publication}

Written consent for publication was obtained.

\section{Copyright}

(c) The Author(s) 2020. 


\section{REFERENCES}

1. Cohanzad S. Extensive metoidioplasty as a technique capable of creating a compatible analogue to a natural penis in female transsexuals. Aesthetic Plast Surg 2016;40:130-8.

2. Djordjevic ML, Bizic M, Stanojevic D, et al. Urethral Lengthening in metoidioplasty (female-to-male sex reassignment surgery) by combined buccal mucosa graft and labia minora flap. Urology 2009;74:349-53.

3. Djordjevic ML, Bizic MR. Comparison of two different methods for urethral lengthening in female to male (metoidioplasty) surgery. $J$ Sex Med 2013;10:1431-8.

4. Hage JJ, van Turnhout AA. Long-term outcome of metaidoioplasty in 70 female-to-male transsexuals. Ann Plast Surg 2006;57:312-6.

5. Hage JJ, Torenbeek R, Bouman FG, Bloem JJ. The anatomic basis of the anterior vaginal flap used for neourethra construction in femaleto-male transsexuals. Plast Reconstr Surg 1993;92:102-8; discussion 109.

6. Takamatsu A, Harashina T. Labial ring flap: a new flap for metaidoioplasty in female-to-male transsexuals. J Plast Reconstr Aesthet Surg 2009;62:318-25.

7. Selvaggi G, Hoebeke P, Ceulemans P, et al. Scrotal reconstruction in female-to-male transsexuals: a novel scrotoplasty. Plast Reconstr Surg 2009;123:1710-8.

8. Djinovic RP. Metoidioplasty. Clin Plast Surg 2018;45:381-6.

9. Chen ML, Reyblat P, Poh MM, Chi AC. Overview of surgical techniques in gender-affirming genital surgery. Transl Androl Urol 2019;8:191-208.

10. Veerman H, de Rooij FPW, Al-Tamimi M, et al. Functional outcomes and urological complications after genital gender affirming surgery with urethral lengthening in transgender men. J Urol 2020;204:104-9.

11. Santucci RA. Urethral complications after transgender phalloplasty: strategies to treat them and minimize their occurrence. Clin Anat 2018;31:187-90

12. Morrison SD, Shakir A, Vyas KS, Kirby J, Crane CN, Lee GK. Phalloplasty: a review of techniques and outcomes. Plast Reconstr Surg 2016;138:594-615.

13. Al-Tamimi M, Pigot GL, Elfering L, et al. Genital gender-affirming surgery in transgender men in the netherlands from 1989 to 2018 : the evolution of surgical care. Plast Reconstr Surg 2020;145:153e-61.

14. Berli JU. Discussion: genital gender-affirming surgery in transgender men in the netherlands from 1989 to 2018: the evolution of surgical care. Plast Reconstr Surg 2020;145:162e-3.

15. Frey JD, Poudrier G, Chiodo MV, Hazen A. A systematic review of metoidioplasty and radial forearm flap phalloplasty in female-to-male transgender genital reconstruction: is the "ideal" neophallus an achievable goal? Plast Reconstr Surg Glob Open 2016;4:e1131.

16. Giraldo F, Mora MJ, Solano A, Abehsera M, Ferrón M, Smith JM. Anatomic study of the superficial perineal neurovascular pedicle: implications in vulvoperineal flap design. Plast Reconstr Surg 1997;99:100-8.

17. Elliott SP, Metro MJ, McAninch JW. Long-term followup of the ventrally placed buccal mucosa onlay graft in bulbar urethral reconstruction. J Urol 2003;169:1754-7.

18. Markiewicz MR, DeSantis JL, Margarone JE 3rd, Pogrel MA, Chuang SK. Morbidity associated with oral mucosa harvest for urological reconstruction: an overview. J Oral Maxillofac Surg 2008;66:739-44.

19. Hage JJ. Metaidoioplasty: an alternative phalloplasty technique in transsexuals. Plast Reconstr Surg 1996;97:161-7.

20. Stojanovic B, Bizic M, Bencic M, et al. One-stage gender-confirmation surgery as a viable surgical procedure for female-to-male transsexuals. $J$ Sex Med 2017;14:741-6.

21. Hoebeke P, Selvaggi G, Ceulemans P, et al. Impact of sex reassignment surgery on lower urinary tract function. Eur Urol 2005;47:398-402.

22. Small MP. Becker H. Use of tissue expanders in genitourinary reconstructive surgery for transsexuals. Proceedings of the eleventh Harry Benjamin International Gender Dysphoria Association Symposium. Cleveland, OH; 1989. p. 67. 